\title{
CRÓNICA DE LAS ELECCIONES BRASILEÑAS DE 2002
}

\author{
ANTONIO G. MOREIRA MAUÉS
}

Profesor Adjunto de la Universidad Federal de Pará Doctor en Derecho por la Universidad de São Paulo 
SUMARIO

I. Introducción. II. El proceso de transición. III. El Gobierno Cardoso. IV. LoS actores. V. Los Resultados electorales. VI. Perspectivas CONSTituCIONALES. VII. LA COMPOSICIÓN DEL NUEVO GOBIERNO.- NOTA BIBLIOGRÁFICA. 


\title{
CRÓNICA DE LAS ELECCIONES BRASILEÑAS DE 2002
}

POR

\author{
ANTONIO G. MOREIRA MAUÉS \\ Profesor Adjunto de la Universidad Federal de Pará \\ Doctor en Derecho por la Universidad de São Paulo
}

\section{INTRODUCCIÓN}

A los brasileños nos gusta comparar nuestro país con los demás. Una de las comparaciones más corrientes en los últimos tiempos sostiene que el Brasil, junto a los Estados Unidos y a China, es uno de los tres únicos países cuyo territorio ( 8 millones de $\mathrm{km}^{2}$ ), producto interno bruto $(600 \mathrm{mil}$ millones de dólares) y población (175 millones), se encuentran de modo simultáneo entre los diez más grandes del mundo.

Ese tipo de comparación nos alerta para una dimensión de la cultura nacional, simbolizada por la creencia de que la riqueza de su territorio y el carácter mestizo de su población permitirían a Brasil alcanzar los niveles más elevados de la civilización, ocupando un lugar destacado en el ámbito internacional.

Los orígenes de esa creencia nos remiten al proceso de nuestra independencia. El Estado brasileño se fundó en 1822 como Imperio de Brasil, manteniendo el amplio teritorio de la colonia portuguesa bajo el control de un Estado Unitario. En la base del sistema imperial, que perduró hasta 1889, había una economía esclavócrata, cuya perpetuación era el interés que mantenía unida la alianza de las élites regionales con el poder central. No es mera coincidencia, por lo tanto, que la República se haya proclamado solamente un año después de la tardía abolición de la esclavitud en Brasil. 
Pero esa cultura se desarrolló de forma especial a partir de la década de los 30 , con la exitosa experiencia de una política desarroIlista, que llevó a Brasil a crecer a un promedio del $7 \%$ al año y volverse la más importante economía de Latinoamérica.

Esa política empezó a ser establecida en el largo período de gobierno de Getúlio Vargas, que asumió la Jefatura del Estado en 1930, después de una Revolución que, dividiendo las oligarquías regionales y contando con el apoyo de las clases medias urbanas, derribó a la I República (1889-1930). Después de cuatro años de gobierno revolucionario y tres años bajo la Constitución de 1934, Vargas promovió un auto-golpe en 1937, fundando un régimen autoritario con caracteristicas fascistas, conocido como Estado Nuevo. Depuesto en 1945, cuando las presiones por la redemocratización se intensificaron con el fin de la II Guerra Mundial, Vargas fue reconducido a la Presidencia en 1950, esta vez en elecciones democráticas, suicidándose en el ejercicio de sus funciones en 1954, para impedir un golpe de estado de la derecha contra su gobierno.

En ese período, hubo la modernización del aparato del Estado, con el establecimiento de una administración burocrática, y la promoción del intervencionismo estatal en la economía. Utilizando, aunque de modo incipiente, técnicas de planeamiento, el Estado hizo inversiones en infraestructuras e incentivó la sustitución de importaciones, haciendo que la industria de bienes de producción creciera. Además, se realizó una amplia reforma en la enseñanza y se promulgaron leyes laborales, inaugurando la construcción de una política social en el país.

La unión entre autoritarismo político y desarrollo no se limitó a la Era Vargas. Duró solamente 19 años (1945-1964) la nueva experiencia de gobiernos constitucionales en Brasil, que se basaron en una política de cuño populista que se agotó con la crisis inflacionaria del comienzo de los años 60 y la imposibilidad de atender a las demandas, cada vez más radicalizadas, de la clase obrera. La respuesta a la crisis fue la dictadura militar, en la cual, bajo la apariencia del régimen constitucional de la Carta del 1967, se sucedieron cinco generales-presidentes.

El régimen militar en Brasil, sin embargo, no interrumpió la política desarrollista de los períodos anteriores. Todo lo contrario, se puede afirmar que promovió su profundización, consolidando el Estado como conductor del proceso de crecimiento económico, por medio de la creación y fortalecimiento de grandes empresas estatales. Esa política permitió un crecimiento continuo que, en su ápice (1973), alcanzó 
el nivel del $13 \%$ al año. En el mismo periodo, la dictadura militar vivía su momento de más fuerte represión, utilizando ampliamente la tortura y las ejecuciones sumarias contra la oposición armada y civil.

Ese modelo se apoyaba en la obtención de grandes préstamos externos por el Estado brasileño para financiar el desarrollo. Así, las tasas de crecimiento cayeron cuando las crisis del petróleo (1973 y 1979) y la subida de los tipos de interés disminuyeron la capacidad del Estado brasileño de saldar sus deudas, poniendo la economía en una ruta inflacionaria. Aun así, durante la dictadura militar el país se volvió mayoritariamente urbano e industrial, amplió su clase media y permitió la elevación de la condiciones de vida de los trabajadores, aunque no se haya logrado repartir los frutos del crecimiento económico entre toda su población. Brasil mantiene uno de los peores indices de distribución de renta en el mundo (el $10 \%$ de los más ricos de su población se apropian del $47 \%$ de la renta total) y, según el Índice de Desarrollo Humano (IDH) del Programa de las Naciones Unidas para el Desarrollo (PNUD), ocupaba en 2002 el 73. ${ }^{\circ}$ puesto entre 173 países. Esas disparidades se constatan fácilmente en sus grandes ciudades, donde niveles muy altos de riqueza conviven con situaciones de extrema pobreza.

Ese muy breve relato histórico ayuda a comprender el proceso electoral de 2002 en Brasil. La política brasileña de las últimas décadas tiene su marco en el reto de conciliar desarrollo económico con justicia social, puesto que los ciclos de crecimiento no han venido acompañados de una reducción proporcional de las desigualdades sociales y regionales, las cuales se agravaron en las dos últimas décadas en razón de los sucesivos períodos de recesión.

Desde la redemocratización, todas las elecciones para la Presidencia de la República se realizaron en un ambiente económico inestable. En 1989, la inflación rondaba el $100 \%$ mensual. En 1994, Fernando Henrique Cardoso se eligió Presidente, por la primera vez, pocos meses después de la puesta en marcha de un plan de estabilización económica, el Plan Real, nombre dado a la nueva moneda. En 1998, la segunda elección de Cardoso ocurrió en el contexto de una seria crisis del Plan Real, que llevó a la devaluación del cambio a comienzos de 1999. En 2002, la inflación empezaba a hacerse sentir otra vez y la recesión producía las más grandes tasas de desempleo de la historia del país.

Con el fin del régimen militar, por lo tanto, el país encaraba no solamente el desafío de restablecer las libertades democráticas, sino también el de reorganizar el aparato estatal. La crisis de la política 
desarrollista significó la crisis del propio Estado brasileño, incapaz de disminuir sus compromisos con el empresariado y de atender a las demandas sociales. Hacía falta redefinir la relación de las distintas clases y grupos sociales con el Estado para reponer la economía en una ruta de crecimiento, permitiendo la elevación de los niveles de educación, salud y renta de la población. Esta vez, el desarrollo económico debería venir acompañado de la democracia, con ello el riesgo de que el fracaso en el campo de la economía fuera visto como un fracaso del régimen democrático. Para entender mejor ese dilema, es necesario volver a algunas características del proceso de transición del régimen autoritario en Brasil, para contextualizar las elecciones de 2002.

\section{EL PROCESO DE TRANSICIÓN}

El final del régimen militar en Brasil estuvo marcado por un proceso de transición negociada. Durante el régimen, se había permitido el funcionamiento de un partido de oposición, el "Movimiento Democratico Brasileño» (MDB) - aunque sus cuadros estuvieran constantemente sujetos a la suspensión de sus derechos políticos-, en cuanto los sectores que apoyaban los gobiernos militares se organizaban en la "Alianza Renovadora Nacional» (ARENA). Pese a la ausencia de elecciones directas para la Presidencia de la República, los gobiernos de los Estados y los ayuntamientos más importantes, se mantuvieron las elecciones para los parlamentos, lo que posibilitó que, desde 1974, el MDB fuera ampliando su base electoral, volviéndose mayoritario en los principales Estados de la Federación. Eses resultados manifestaban la insatisfacción con el régimen, que pasó a promover una "apertura" política que tenía como objetivo el relevo de los militares por sus aliados civiles, manteniéndose las restricciones a las libertades partidaria y sindical, además de las elecciones indirectas para los cargos ejecutivos más importantes.

Ese proceso ganó un nuevo impulso a partir de 1979, con la amnistía y la autorización para la organización de nuevos partidos. En 1982 se disputaron elecciones directas para los gobiernos de los Estados, que resultaron en la victoria de la oposición en las principales unidades de la Federación (São Paulo, Rio de Janeiro, Minas Gerais). Junto al crecimiento de la oposición, la incapacidad del gobierno militar en solucionar la crisis económica generó una inédita movilización política de la sociedad en torno a la campaña de las "Directas Ahora". Ese gran movimiento cívico defendía la aprobación de una enmienda cons- 
titucional que convocaba elecciones directas para la sucesión del General João Batista Figueiredo en la Presidencia de la República, que, de acuerdo con las reglas vigentes, debería ser elegido por un Colegio Electoral compuesto por los miembros del Congreso Nacional y representantes de las Asambleas de los Estados, en el cual el régimen militar contaba con mayoría.

Pese a haber sido rechazada la enmienda por el Congreso Nacional, la movilización social en las grandes ciudades dificultaba la continuidad del régimen. Así, la oposición, capitaneada por el PMDB (Partido del Movimiento Democratico Brasileño), buscó el apoyo popular para que su candidato, Tancredo Neves, entonces Gobernador de Minas Gerais, disputara el Colegio Electoral. Con la adhesión de disidentes del régimen, que formaron el Partido del Frente Liberal (PFL), Tancredo logró vencer la disputa contra el candidato del Gobierno, el civil Paulo Maluf.

Ese proceso forzó a una negociación entre la oposición y sectores del régimen, como consecuencia de la misma aceptación de las reglas establecidas para promover la transición, bien como la necesidad de cooptar aquellos sectores para garantizar la mayoría en el Colegio Electoral. De esa negociación resultó un gobierno que restauró en su plenitud las libertades democráticas, pero mantuvo, en su cuadro dirigente y en la forma de conducción de las políticas públicas, un nivel muy alto de continuidad con el régimen autoritario. El mejor ejemplo de esa situación se produjo con la enfermedad que acometió a Tancredo Neves, quitándole su vida antes de la toma de posesión, lo que hizo con que asumiera la Presidencia de la República su vice, José Sarney, que había sido Presidente de ARENA y uno de los principales líderes civiles del régimen.

Como parte de los acuerdos de la transición se encontraba la realización de una Asamblea Constituyente, cuya convocatoria se inspiró en el proceso de transición español. Sin ruptura con la legalidad del régimen autoritario, la Asamblea fue convocada por una enmienda a la Constitución de 1967, atribuyendo poderes constituyentes al Congreso Nacional que debería ser elegido en 1986. Ese modelo de constituyente ya había sido utilizado para la elaboración de la primera Constitución republicana (1891) y de la Constitución de 1946, después de la caída del Estado Nuevo, siempre con el objetivo de limitar los poderes de la Asamblea. Sin embargo, la amplia participación de las organizaciones de la sociedad civil en el proceso permitió que la elaboración de la nueva Constitución incorporara muchas de sus propuestas. 
Durante la Constituyente se destacó la incapacidad del PMDB, que en ella tenía mayoría absoluta, para articular una mayoría que integrase un eje de negociación al cual se sumaran los otros partidos. Eso se explica, en parte, por las mismas condiciones en que esa mayoría se obtuvo. Después del fin de la dictadura militar, el PMDB, como partido del gobierno, atrajo para sus filas muchos de los antiguos miembros del régimen, perdiendo identidad ideológica. Además, las elecciones para la Constituyente se realizaron en cuanto estaba en curso un plan de estabilización económica, conocido como Plan Cruzado, que lograra frenar la inflación y contaba con amplio apoyo popular. Después de las elecciones, las medidas del Plan Cruzado fueron perdiendo vigor, provocando la vuelta de la inflación, lo que debilitó al PMDB y hizo explícitas sus divergencias internas.

Así, la Constituyente brasileña no consolidó los acuerdos que permitieron la transición del régimen autoritario, ni estableció un nuevo pacto entre las clases y grupos sociales que otorgara estabilidad al Estado. Las propuestas victoriosas en la Constituyente resultaron de los sucesivos acuerdos de fracciones del PMDB con partidos a su derecha $y$ a su izquierda, lo que produjo un texto constitucional particularmente conflictivo y con bajo nivel de consenso. Además, los dos años que tardaron los trabajos constituyentes y la independencia de los parlamentarios, que reforzaba la influencia de los grupos de interés en la Asamblea, ampliaron demasiado la materia constitucional $y$, por lo tanto, la posibilidad de conflictos sobre su contenido.

El ciclo de la transición se cerraría con las elecciones directas para Presidente de la República, realizadas en 1989. El desgaste de los dos más grandes partidos, que habían conducido la transición, PMDB y PFL, hizo con que sus candidatos fueran estrepitosamente derrotados. Favorecidos por una elección aislada, en la cual ningún otro cargo estaba en disputa, dos candidatos de pequeños partidos llegaron a la 2. ${ }^{\text {a }}$ vuelta: Fernando Collor de Mello, del Partido de la Reconstrucción Nacional (PRN), disidente del PMDB que había empezado su carrera política en ARENA y ex gobernador del pequeño Estado de Alagoas, y Luiz Inácio Lula da Silva, líder del Partido de los Trabajadores (PT), de izquierda socialista, fundado en 1980 y que todavía luchaba para establecerse en todo el país. Pese a sus diferencias, los dos se presentaban al electorado como candidatos sin compromisos con las élites políticas $y$, por lo tanto, encarnaban la posibilidad de renovación. Con el macizo apoyo del empresariado, Collor venció las elecciones. 
La disputa electoral demostraba que el sistema político brasileño no se había consolidado con la Constitución de 1988. El Gobierno Collor tampoco contribuyó para esa consolidación. Sin un gran partido que lo apoyara en el Congreso Nacional, y enfrentando varias denuncias de corrupción, el primer presidente elegido en Brasil después de 29 años fue objeto de un proceso de impeachment que lo apartó del cargo en 1992. El bienio siguiente estuvo marcado por grandes incertidumbres. Asumió la Presidencia de la República Itamar Franco, vice de Collor y oriundo del antiguo MDB, que había logrado escapar a las denuncias contra el Gobierno, pero no logró articular una base política consistente. Pese a ese difícil cuadro, el respeto a las normas constitucionales en el proceso contra Collor y su relevo por Itamar Franco mantenía un parámetro normativo en medio a la crisis, lo que señalaba que las elecciones programadas para 1994 se encargarían de arreglar el mapa político.

\section{EL GOBIERNO CARDOSO}

Pese a que la Constitución de 1988 optara por un Estado intervencionista y por la nacionalización de la economía, manteniendo los marcos de una política desarrollista, los años que sucedieron a su promulgación se destacan por una convergencia de parte significativa de las élites empresariales y políticas en torno al programa neoliberal. De acuerdo con ese programa, la necesaria reforma del Estado brasileño debería ser pautada por la apertura comercial y financiera, por la desregulamentación de la economía y por las privatizaciones; la estabilidad económica y la victoria sobre la inflación se obtendrían por medio de políticas que permitieran el ingreso macizo de capitales financieros en el país. Después de tentativas fracasadas de solucionar la deterioración de la economía, Itamar Franco convoca a Fernando Henrique Cardoso, entonces Ministro de las Relaciones Exteriores, para ocupar el Ministerio de Hacienda. Cardoso se había vuelto uno de los intelectuales más respetados de Brasil antes de ingresar en la política, habiendo ocupado el cargo de Senador por São Paulo a partir de 1983. Durante la Constituyente, Cardoso fue uno de los líderes de la disidencia del PMDB que fundó el Partido de la Social Democracia Brasileña (PSDB), con el objetivo de ofrecer una opción política de centro para los electores descontentos con el PMDB.

En torno a su liderazgo, se formó un nuevo bloque de poder. Habiendo logrado con el Plan Real, en pocos meses, disminuir de modo sensible la inflación, Cardoso vence en primera vuelta las elec- 
ciones de 1994, apoyado por una alianza entre el PSDB y el PFL, a la cual se unió posteriormente el PMDB. Así, los conductores del proceso de transición volvían a estar al frente del gobierno, aunque pasaron a aplicar un programa distinto al que habia presidido la elaboración de la Constitución de 1988, lo cual hizo de la realización de reformas constitucionales una de sus principales banderas.

La alianza fue reconducida al poder en las elecciones de 1998, a pesar de obtener menos votos. El segundo mandato de Cardoso se caracterizó por crecientes dificuldades en el campo económico, que produjeron nuevas resistencias al desarrollo del programa neoliberal. Preso a las áncoras de su propia política, que le impedian orientar la economía en el sentido del crecimiento, y viendo cómo las disputas por su sucesión se encarecían en el interior de la alianza, el Gobierno fue paulatinamente perdiendo el apoyo de la población, cada vez más propensa a votar en la oposición.

Los pocos meses que nos separan del final del mandato de Cardoso hacen difícil emitir un juicio sobre sus ocho años de gobierno. Para los que hacen un análisis positivo, su gran victoria ha sido mantener la inflación bajo control, lo que permitió reorganizar la actividad económica en Brasil. Además, hubo mejoras en los indicadores de escolarización, especialmente en la enseñanza básica; reducción de la mortandad infantil; creación de nuevos programas de ayuda a los pobres, desvinculados del clientelismo político; y racionalización del aparato estatal, con la creación de mecanismos de control sobre la capacidad de endeudamiento del sector público.

Ya para los críticos, se destaca que el control de la inflación se hizo al coste de un ínfimo crecimiento económico $(2,3 \%$ al año) y del aumento del déficit público, provocado por los altos tipos de interés fijados por el mismo Gobierno. Además, no hubo mejoras sensibles en la distribución de la renta, habiendo incluso retrocedido la participación de los sueldos en la renta nacional. Altos niveles de desempleo y aumento de la violencia urbana también componen la herencia de Cardoso.

\section{LOS ACTORES}

En las elecciones de 2002 se eligieron el Presidente de la República, 513 Diputados, elegidos por sistema proporcional, $54 \mathrm{Se}$ nadores (2/3 de la Casa), elegidos por sistema mayoritario, y 26 Gobernadores y Asambleas Legislativas de los Estados, además del Gobernador del Distrito Federal y su Cámara Legislativa. 
Para la Presidencia de la República, se presentaron:

a) Luiz Inácio Lula da Silva, por la Coalición "Lula Presidente", formada por el Partido de los Trabajadores (PT), Partido Liberal (PL), Partido Comunista de Brasil (PCdoB), Partido de la Movilización Nacional (PMN) y Partido Comunista Brasileño (PCB). Oriundo del Nordeste del país, de donde partió con su familia para huir de la pobreza que caracteriza esa región, Lula se convirtió en el Presidente del Sindicato de los Metalúrgicos de São Bernardo y Diadema, en el Estado de São Paulo, donde se concentra la producción automobilística del país. Después de liderar las huelgas de la categoría al final de la década de los 70, que contribuyeron de modo decisivo para la redemocratización, Lula funda el PT con otros líderes sindicales, sectores de la Iglesia Católica vinculados a la Teología de la Liberación, intelectuales y grupos oriundos de la lucha armada contra la dictadura militar. Después de la derrota contra Fernando Collor en la 2. ${ }^{a}$ vuelta de las elecciones de 1989, Lula se afianzó como un líder nacional y, pese a haber sufrido nuevas derrotas en 1994 y 1998, siempre amplió su base electoral. Lo mismo sucedió con el PT, que llegó al gobierno de muchas de las ciudades más importantes del país, además de algunos Estados, y constantemente aumentaba su representación en el Congreso Nacional;

b) José Serra, por la Coalición "Gran Alianza", formada por el Partido de la Social Democracia Brasileña (PSDB) y el Partido del Movimiento Democrático Brasileño (PMDB). Serra empezó su trayectoria política como Presidente de la Unión Nacional de los Estudiantes, habiéndose exiliado después del golpe militar de 1964. Al volver a Brasil, en el final de la década de 70 , se convirtió en uno de los más renombrados cuadros burocráticos del PMDB, partido por el cual se eligió diputado constituyente en 1986. Fundador del PSDB, obtuvo, con expresiva votación, un escaño de Senador por São Paulo, en 1994. Fue Ministro de Planeamiento y Ministro de la Salud en los Gobiernos de Cardoso. En ese último cargo, logró consolidar una imagen de administrador competente, por medio de políticas como el tratamiento del SIDA y la reducción de los índices de mortandad infantil;

c) Anthony Garotinho, por la Coalición «Frente Brasil Esperanza", formada por el Partido Socialista Brasileño (PSB), Partido Laborista Cristiano (PTC) y Partido General de los Trabajadores (PGT). Ex Gobernador de Rio de Janeiro (1999-2002), el segundo Estado más importante de la Federación, Garotinho hizo su carrera política bajo la protección de Leonel Brizola, líder histórico del laborismo. Después de 
asumir el Gobierno de Rio, disputó y perdió contra Brizola el liderazgo del Partido Democrático Laborista (PDT), encontrando abrigo en el PSB. Garotinho pretendió presentarse en la campaña como un candidato independiente de las élites políticas y económicas, asumiendo una postura demagógica. Teniendo en cuenta la pequeña estructura del PSB, su candidatura recibió un fuerte apoyo de la nuevas Iglesias evangelistas, que cada vez cuentan con mayor representación en la política nacional;

d) Ciro Gomes, por la Coalición «Frente Laborista», formada por el Partido Popular Socialista (PPS), Partido Democrático Laborista (PDT) y Partido Laborista Brasileño (PTB). Ex Gobernador del Estado de Ceará (1991-1994) y ex Ministro de Hacienda (1994), Ciro rompió con el PSDB en 1998, criticando la conducción de la política económica, y lanzó su candidatura a la Presidencia de la República por el pequeño PPS, oriundo del antiguo Partido Comunista Brasileño. Desde las elecciones anteriores, Ciro buscaba presentarse como una alternativa de centro, menos radical que el PT, para aquellos que no querían la continuidad del modelo seguido por Cardoso. De acuerdo con las encuestas, llegó a tener la posibilidad de disputar la segunda vuelta con Lula, pero su alianza con sectores del PFL, el aparecimiento de denuncias de corrupción que involucraban los partidos que lo apoyaban, además de sus desastrosas declaraciones a la prensa, desestabilizaron la imagen del candidato, al mismo tiempo que Lula ocupaba el espacio del centro con la moderación de sus propuestas;

e) José Maria de Almeida, por el Partido Socialista de los Trabajadores Unificado (PSTU), formado por corrientes de izquierda expulsadas del PT, con base en el movimiento sindical pero sin resultados electorales significativos;

f) Rui Pimenta, por el Partido de la Causa Obrera (PCO), minúsculo agrupamiento de tendencia trotskista.

Aunque no sea una tarea fácil caracterizar las candidaturas, algunas afirmaciones se puden hacer acerca de los principales contendientes. En el caso de Lula, la fuerza de su candidatura resultaba no solamente de su prestigio personal y carisma, lo que incluía su identificación como la principal voz de la oposición en Brasil. En los trece años que separaron su primera tentativa de la victoria el año pasado, el PT se convirtió en un partido sólidamente establecido en todo el país, capaz de contar con el apoyo de muchas organizaciones populares y sindicales en todo el territorio, destacándose la Central Única de los Trabajadores (CUT). Paralelamente, Lula y el PT lograron, en esa 
elección, hacer alianzas hacia el centro, representadas por la participación del PL en la coalición. Ese pequeño partido ofreció el candidato a Vicepresidente de la República, el Senador por Minas Gerais, José Alencar, uno de los más importantes empresarios del sector textil del país. La alianza simbolizaba que el PT, pese a su identidad socialista, haría un gobierno moderado, buscando la colaboración entre capital y trabajo para la solución de los problemas nacionales. Esa opción política ha convencido a una buena parte de los sectores empresariales $y$ de las clases medias que todavía temían el partido y su candidato.

Respecto a José Serra, sus cualidades y defectos personales se han vuelto menos importantes que su vinculación al Gobierno Cardoso. Se hacía difícil para el candidato evitar el rechazo de los electores que no apoyaban la continuidad de la política del Gobierno. Además, como luego veremos, su coalición ya no representaba todos los sectores que habían sostenido a Cardoso y, al ser el candidato apoyado por el sector financiero y los más importantes grupos empresariales del país, Serra no lograba volver creíble su promesa de cambio en los rumbos de la economía.

En la lista de partidos arriba mencionados, hay un gran ausente: el Partido del Frente Liberal (PFL), que no apoyó oficialmente a ninguno de los candidatos, dividiéndose entre José Serra y Ciro Gomes. Negándose a continuar como socio minoritario en el gobierno, y no creyendo en la posibilidad de victoria de Serra, el PFL intentó articular una candidatura propia para la Presidencia: la de la Gobernadora del Estado de Maranhão, Roseana Sarney, hija del ex presidente José Sarney. Esa estrategia sufrió un colapso cuando se hizo pública la recaudación ilegal de fondos para la campaña de Roseana, que tuvo que renunciar a su candidatura. Responsabilizando a sectores del Gobierno por la divulgación de los hechos, muchos líderes del PFL no aceptaron ingresar nuevamente en la alianza gubernamental, adhiriéndose a Ciro Gomes. Con raíces muy firmes en la Región Nordeste, el PFL es el principal partido de derechas en Brasil, habiendo participado en todos los gobiernos desde el régimen militar. Así, constituye una novedad en la política brasileña que el PFL se encuentre en la oposición, el mismo caso que otro partido de derechas, el Partido Progresista Brasileño (PPB), heredero de ARENA, que, en razón de su contienda electoral con el PSDB en el Estado de São Paulo, tampoco apoyó oficialmente a ningún candidato.

Cabe destacar también que los programas de todos los candidatos preconizaban cambios en la gestión de la economía. Durante el mandato de Cardoso, la población se había contentado con la caí- 
da de los índices de la inflación, aunque eso no significara una mejor distribución de la renta. En los últimos años de su gobierno, sin embargo, la necesidad de orientar la economía hacia una distribución de la riqueza del país volvió a ocupar el centro del debate político, replanteando el viejo dilema de la historia contemporánea de Brasil.

Consciente del estado de crisis de la economía, que había forzado al Brasil a pedir una ayuda emergencial al FMI dos meses antes de las elecciones, la dirección del PT supo presentar su candidato como aquél que mantendría una gestión económica responsable - teniendo en cuenta los cambios en el programa del partido- $y$, al mismo tiempo, desarrollaría una política social más activa. La trayectoria del partido y del candidato afianzaban esa perspectiva de cambio con responsabilidad, de una forma que José Serra no logró alcanzar.

\section{LOS RESULTADOS ELECTORALES}

En la primera vuelta de las elecciones, realizada el 6 de octubre, comparecieron 94.804 .126 electores $(82,26 \%$ del total), con el siguiente resultado (los porcentajes se refieren a los votos válidos, excluídos blancos y nulos):

Lula: $39.454 .692(46,44 \%)$

Serra: $19.705 .061(23,20 \%)$

Garotinho: $15.179 .879(17,87 \%)$

Ciro: $10.170 .666(11,97 \%)$

José Maria: $402.232(0,47 \%)$

Rui Pimenta: 38.619 (0,05\%)

El escaso margen que separó Lula de la victoria en la 1. a vuelta, para la cual se exige la mayoría absoluta de los votos válidos, ya mostraba que, muy difícilmente, Serra podría arrebatarle a Lula esa ventaja en la 2." vuelta. La perspectiva de victoria del candidato del PT aumentó con la rápida adhesión a su candidatura de los partidos que apoyaron a Garotinho y Ciro, los cuales también pidieron a sus electores que votaran en Lula. Ante las pocas posibilidades de ampliación de su base electoral, la campaña de Serra intentó crear un clima de 
inquietud en el país, afirmando que Brasil repetiría las crisis de Argentina y Venezuela caso el candidato de la oposición fuese elegido. Lula logró impedir la difusión de esa idea atrayendo hacia su candidatura líderes empresariales y sindicales, demostrando que gobernaría con un amplio apoyo social y político. El resultado final, en que Lula obtuvo 52.793 .364 de votos $(61,27 \%)$ contra $33.370 .739(38,73 \%)$ de Serra, expresa la dimensión de la base social de la candidatura victoriosa.

El análisis del resultado de la 2. ${ }^{a}$ vuelta de acuerdo con las regiones del país, destaca la ampliación de la ventaja de Lula en el Sureste, la más rica de Brasil, en que obtuvo $63,01 \%$, lo cual muestra sú fuerza entre los electores de las ciudades más grandes, aunque haya recibido un porcentaje de votos inferior respecto a su media nacional en São Paulo $(55,4 \%)$. Serra obtuvo sus mejores resultados en las Regiones Norte $(41,82 \%)$ y Centro-Oeste $(42,71 \%)$, caracterizadas por un electorado disperso en el interior del país, lo cual muestra la fuerza electoral que el Gobierno todavía poseía entre los electores de los pueblos. siguiente:

En la elección para el Congreso Nacional, el resultado fue el

a) Cámara de los Diputados

PT: 91

PFL: 84

PMDB: 73

PSDB: 72

PPB: 49

PL: 26

PTB: 26

PSB: 24

PDT: 21

PPS: 15

PCdoB: 12

Otros: 20 
b) Senado Federal (el número entre paréntesis indica los escaños del partido en la próxima Legislatura)

\author{
PFL: 14 (19)
}

PT: 10 (14)

PMDB: 9 (20)

PSDB: 8 (11)

PDT: 4 (5)

PSB: 3 (4)

PTB: 2 (3)

PL: 2 (3)

PPS: 1

PSD: 1

Pese al notable crecimiento de sus cuadros en la Cámara y en el Senado, el resultado de las legislativas indica que el PT deberá contar con el apoyo de otros partidos para gobernar, empezando por aquellos que se aliaron a Lula en la 2. ${ }^{\text {a }}$ vuelta, como PPS, PDT, PTB y PSB. Es también probable que los partidos de la base gubernamental reciban nuevas adhesiones, puesto que el sistema electoral de lista abierta y la ausencia de sanciones, como la pérdida del mandato, facilitan el cambio de chaqueta en Brasil.

Aun asi, esa alianza no consolida la mayoría absoluta en la Cámara y en el Senado, lo cual hace necesario negociar con la oposición, especialmente para la aprobación de reformas constitucionales, las cuales exigen un quórum de $3 / 5$ en cada una de las Casas. Con el PMDB, los entendimientos ya están en marcha, facilitados por el hecho de que algunos de sus líderes se adhirieron a Lula desde la 1. ${ }^{a}$ vuelta.

Pero el cuadro electoral no se completa sin el examen de las elecciones en los Estados, donde el PT no cosechó resultados ímportantes, aunque haya disputado la $2 .{ }^{\text {a }}$ vuelta en muchos de ellos. EI PSDB mantuvo el Gobierno de São Paulo, el principal Estado de la Federación, y eligió el Gobernador de Minas Gerais, el segundo Estado en población. En Rio de Janeiro, se eligió Rosinha Garotinho, del PSB, esposa del candidato a Presidente, lo cual muestra la continuidad de su dominio político en el Estado. EI PT eligió por la segunda vez sus Gobernadores de Acre, pequeño Estado en la Amazonía, y de Mato 
Grosso do Sul, en el Centro-Oeste, importante por su actividad agropecuaria, habiendo conquistado también el Estado de Piauí, en el Nordeste. El cuadro general se compone finalmente de la siguiente forma:
a) PSDB: 7
b) PMDB: 5
c) PFL: 4
d) PSB: 4
e) PT: 3
f) PPS: 2
g) PDT: 1
h) SL: 1

Considerando la alianza de la 2. ${ }^{a}$ vuelta, Lula cuenta con el apoyo solamente de 11 Gobernadores de Estado. Ese dato resulta importante porque los Gobernadores poseen un alto grado de influencia sobre los diputados y senadores de su Estado, lo cual significa que la aprobación de las propuestas más polémicas necesita de su adhesión. Además, otro problema político-constitucional que permanece sin solución satisfactoria en Brasil es el pacto federativo. En los años de Cardoso hubo una tendencia a la concentración de los recursos financieros en el gobierno central, al mismo tiempo que los ingresos de los Estados se vinculaban al pago de su deuda con la Unión. Ese cuadro viene dificultando, en muchos casos, el desarrollo de políticas públicas por parte de los Estados, lo cual impone la realización de una reforma tributaria.

El resultado electoral, por lo tanto, indica la ascensión de un fuerte partido de izquierdas, el PT, junto a la continuación del PSDB en la dirección de algunos de los principales Estados, mostrando una tendencia de más equilibrio entre gobierno y oposición y un carácter ideológicamente más plural en la política brasileña.

\section{PERSPECTIVAS CONSTITUCIONALES}

Los ocho años del Gobierno Cardoso estuvieron marcados por el signo de la reforma constitucional. En ese período, se aprobaron 35 
enmiendas a la Constitución de 1988, algunas de ellas modificando sustancialmente el texto original. De entre las más importantes podemos citar:

a) Enmiendas al orden económico: esas enmiendas permitieron eliminar los monopolios de empresas estatales en distintos sectores, como petróleo y telecomunicaciones, o la exigencia de nacionalización de determinadas actividades, como la explotación de los recursos minerales. Así, se hizo posible la aplicación en Brasil del programa neoliberal.

b) Enmiendas de carácter fiscal y tributario: como suele pasar en los regímenes autoritarios, la dictadura militar se caracterizó por el centralismo, limitando la autonomía política y financiera de los Estados y Municípios. De ahi que la Constituyente haya recibido una demanda muy fuerte favorable al refuerzo de las entidades federativas, de lo cual resultó una redistribución de los ingresos tributarios que les favoreció. La continuidad de la crisis fiscal del Estado brasileño, sin embargo, produjo un conjunto de enmiendas que crearon nuevos tributos $y$ disminuyeron los traspasos para Estados y Municipios, aumentando el porcentaje de los ingresos destinados a la Unión.

c) Enmiendas de reforma del Estado: se destacan aqui la reforma administrativa, que permitió el despido de funcionarios públicos y la fijación de límites máximos de remuneración en el sector público, y la reforma de la seguridad social, que aumentó los requisitos para la jubilación.

Los temas objeto de esas reformas muestran el carácter excesivamente analítico de la Constitución Brasileña. Como mencionamos, la elaboración de la Constitución de 1988 no estuvo pautada por el consenso, lo que dificultó el mantenimiento de los acuerdos que se celebraron en su interior. Así, la mayoría política que llevó Cardoso al gobierno reformó la Constitución todas las veces que se hizo necesario para la consecución de su propio programa. Con independencia de cualquier juicio sobre el mérito de esas reformas, se debe observar que ellas significan que la Constitución de 1988 no fue tomada como el marco dentro del cual se procesan los conflictos políticos, sino que ella misma se convirtió en el objeto de esos conflictos.

De eso resulta una inestabilidad constitucional que dificulta la consolidación del régimen democrático. Hay que reconocer que la dimensión electoral de la democracia viene funcionando correcta- 
mente en los últimos años, incluso permitiendo la alternancia en el gobierno central en las últimas elecciones. Sin embargo, debemos coṇsiderar que la democracia no se estabiliza sólo con la adopción de la regla de la mayoría, sino que requiere un complejo mecanismo de división de los poderes que permita el respeto de los derechos de los ciudadanos y la convivencia entre las diferentes corrientes políticas.

Las dificultades de esa consolidación se manifiestan, por ejem$\mathrm{p}^{\prime} \mathrm{o}$, en las cerca de tres mil "acciones directas de inconstitucionali'lad» (ADIns) planteadas desde la promulgación de la Constitución. ' Modalidad del control abstracto en Brasil, las ADIns fueron favorecidi s por la Constitución de 1988, que otorgó legitimación activa, ade$\mathrm{m}$ `s de los órganos políticos de la Unión y de los Estados, a los partidcs políticos, al Consejo Federal del Colegio de Abogados, a las confederaciones sindicales y a las entidades de clase de ámbito nacional. La amplia legitimación explica en parte el número elevado de acciones. Sin embargo, el constante recurso al Supremo Tribunal Federal muestra la incapacidad del sistema político de desarrollar mecanismos eficaces de negociación, que logren la adhesión de la sociedad y de las minorías políticas a las propuestas del gobierno. En consecuencia, se establece una constante disputa sobre el contenido de la Constitución, que no viene siendo resuelta satisfactoriamente por el Supremo Tribunal Federal, ampliando la incertidumbre del marco constitucional.

Una parte significativa de las ADIns fue promovida por los partidos de la oposición contra "medidas provisionales", las cuales constituyen un caso ejemplar de los problemas que la democracia constitucional enfrenta en Brasil. La Constitución de 1988, cambiando el instituto de los decretos-ley que había sido utilizado por los gobiernos militares, atribuyó al Presidente de la República la competencia para dictar medidas provisionales, con fuerza de ley, en casos de relevancia y urgencia. Las medidas provisionales deberían ser inmediatamente sometidas al Congreso Nacional para su conversión en ley, perdiendo eficacia en 30 días. Pocos meses después de la promulgación de la Constitución ocurrió que una de esas medidas no fue votada por el Congreso dentro de ese plazo, lo cual hizo que el Presidente la dictara nuevamente, con la aceptación del Congreso. Eso abrió un precedente que fue utilizado ampliamente por el Gobierno Cardoso, tendiendo a la violación del principio de la división del poder. Las medidas provisionales se convirtieron así en instrumento de legislación no solamente en casos de urgencia y relevancia, sino en todos los temas en que el Gobierno no deseaba una deliberación del Congreso. Orientando su mayoría parlamentaria para no votar las 
medidas, el Poder Ejecutivo se veía libre, con el permiso del Supremo Tribunal Federal, para dictar la medida cada 30 días, incluso adaptando su contenido a las necesidades de la coyuntura, con daños previsibles para la seguridad jurídica. En 2001, finalmente, se intentó contener el abuso con la aprobación de la Enmienda Constitucional $n .^{\circ} 32$, que ha limitado definitivamente la duración de las medidas provisionales a 120 días.

De entre los factores que explican esa inestabilidad se encuentra, sin lugar a dudas, el sistema de partidos. En el presidencialismo, la gobernabilidad exige que el poder ejecutivo cuente con mayoría en el poder legislativo que, de otra forma, forzará el gobierno a difíciles negociaciones a cada votación importante. La ausencia de cláusulas de barrera electoral, la amplitud de los espacios gratuitos de propaganda electoral, el control de los aparatos de los gobiernos de los Estados por élites políticas regionales, la amplia posibilidad de coaliciones, entre otros motivos, explican la pulverización del sistema de partidos brasileño, que genera un "presidencialismo de coalición", en que el partido victorioso en las elecciones presidenciales debe buscar el apoyo de otros para gobernar.

Ese cuadro perjudica la estabilidad política, puesto que la obtención de apoyo muchas veces toma como base el dinero público, para atender a la clientela de los parlamentarios, y facilita la acción de los grupos de interés. Una de sus expresiones es el proceso de reforma constitucional, que no logró un nivel de consenso más elevado que el texto original, pues las negociaciones que se hicieron para la aprobación de las enmiendas no fueran comandadas por líderes que, teniendo gran representatividad social y control sobre sus partidos, pudieran afianzar compromisos duraderos.

Una reflexión sobre esos problemas se hace necesaria porque el programa del nuevo gobierno se estructura alrededor de cinco reformas: tributaria, seguridad social, agraria, laboral y política. Todas ellas, en mayor o menor medida, implican nuevos cambios en la Constitución. El desafío, por lo tanto, está claro: el Gobierno Lula deberá buscar solucionar el problema de legitimidad constitucional, realizando reformas que cuenten con un amplio consenso social y político y puedan estabilizar el marco constitucional. No hay otra alternativa, a no ser insistir en gobernar por medio de medidas provisionales, muchas veces en detrimento de la Constitución, o bien aceptar la negociación con los sectores más conservadores del Congreso Nacional. 


\section{LA COMPOSICIÓN DEL NUEVO GOBIERNO}

Después de un largo proceso de negociación con los distintos partidos que le apoyaron en la $1 .^{\mathrm{a}}$ y en la $2 .^{\mathrm{a}}$ vuelta, Lula presentó sus Ministros, confirmando un gran cambio: por la primera vez, desde el fín del régimen militar, hubo una significativa renovación de la élite dirigente. Además de líderes del PT y de los partidos de izquierdas, incluyendo a Ciro Gomes, Lula ha nombrado para el Ejecutivo federal importantes líderes empresariales.

De entre sus propuestas iniciales, Lula destacó el Programa Fome Zero, con el objetivo de eliminar la miseria en el país. Además de su significación social, la definición de esa prioridad tiene el objetivo de demostrar un cambio de orientación en las políticas públicas y el compromiso con la distribución de la renta.

El ambiente económico, no obstante, sigue muy desfavorable. Las incertidumbres sobre la política que sería adoptada por el nuevo gobierno favorecieron la especulación y la devaluación del real, produciendo los niveles más altos de inflación desde la adopción de la moneda, en 1994. Además de reconocer sus límites en la conducción de la política económica, el Gobierno Lula se viene esforzando en conquistar la confianza de los inversores internacionales, en cuanto se hacen las reformas que permitan disminuir la dependencia del capital externo.

Otra importante innovación ha sido la creación del Consejo de Desarrollo Económico y Social, que tiene como objetivo crear un canal permanente de diálogo donde se puedan pactar las propuestas de reforma. La eficacia de ese Consejo parece ser fundamental para que el Gobierno Lula supere las resistencias de la oposición y consolide una nueva forma de relacionamento del Estado con la sociedad.

Pese a las dificultades económicas, Lula tomó posesión con un amplio apoyo político. La inédita fiesta popular que lo recibió en Brasília expresa la esperanza que la población le otorga. Sin embargo, eso también significa la expectativa de atendimiento de demandas sociales reprimidas hace décadas. Las elecciones de 2002 ofrecieron a una nueva élite política, con bases muy sólidas en los movimientos sociales, la oportunidad de vincular desarrollo y justicia social, reorganizando el Estado brasileño. El problema está en saber el tiempo que la población concederá al nuevo gobierno para que esa vinculación se concrete. 


\section{NOTA BIBLIOGRÁFICA}

Para los lectores que deseen una información complementaria acerca de los temas tratados en esta crónica, sugerimos las siguientes obras:

a) Síntesis de la historia de Brasil: Boris Fausto, História do Brasil (Ed. USP); Francisco IGLÉsIAS, Trajetória política do Brasil: 1500-1964 (Ed. Companhia das Letras) (hay edición española en MAPFRE).

b) Sobre la crisis del desarrollismo y el proceso de transición: Alfred Stepan (Org.), Democratizando o Brasil (Ed. Paz e Terra); Bolívar LAMOUNIER (Org.), De Geisel a Collor: o balanço da transição (Ed. Idesp); Brasilio SALLUM JR., Labirintos. Dos Generais à Nova República (Ed. Hucitec); José Luís FIORI, Em busca do dissenso perdido (Ed. Insight); Thomas SKIDMORE, Brasil: de Castelo a Tancredo (Ed. Paz e Terra).

c) Sobre los problemas del orden constitucional: Antonio G. Moreira MAUÉs (Org.), Constituição e Democracia (Ed. Max Limonad); Argelina CHEIBUB FigueIREdo y Fernando LIMONGI, Executivo e Legislativo na nova ordem constitucional (Ed. FGV); José Eduardo FARIA, O Brasil pós-constituinte (Ed. Graal).

d) Sobre el PT y Lula: André SINGer, O PT (Ed. Publifolha); Denise Paraná, Lula: o filho do Brasil (Ed. Fundação Perseu Abramo); Margaret KECK, PT: a lógica da diferença (Ed. Ática); Rachel Meneguello, PT: a formação de um partido (19791982) (Ed. Paz e Terra). 